\title{
Processing and Characterization of a Polypropylene Biocomposite Compounded with Maleated and Acrylated Compatibilizers
}

\author{
Brent A. Nerenz, Michael A. Fuqua, Venkata S. Chevali, and Chad A. Ulven \\ Department of Mechanical Engineering, North Dakota State University, 111 Dolve Hall NDSU Dept 2490, \\ P.O. Box 6050, Fargo, ND 58108, USA \\ Correspondence should be addressed to Chad A. Ulven, chad.ulven@ndsu.edu
}

Received 6 September 2011; Accepted 16 January 2012

Academic Editor: Luqman Chuah Abdullah

Copyright () 2012 Brent A. Nerenz et al. This is an open access article distributed under the Creative Commons Attribution License, which permits unrestricted use, distribution, and reproduction in any medium, provided the original work is properly cited.

Polypropylene (PP) biocomposites containing $20 \mathrm{wt} . \%$ sunflower hull as a particulate reinforcement were compounded and tested under tensile, flexural, and impact loadings. The incorporation of the sunflower hull without compatibilizer resulted in diminished tensile strength and impact energy absorption but increased flexural strength and both tensile modulus and flexural modulus when compared to neat PP. Formulations containing three different chemical compatibilizers were tested to determine their effectiveness in improving the interfacial adhesion between the fiber surface and PP chains. Maleic anhydride grafted with PP (MA-g-PP) achieved greater improvements in tensile strength but reduced impact strength in comparison to an acrylic-acidgrafted PP compatibilizer (AA-g-PP). The molecular weight, graft level, and the ability to affect strength, modulus, and absorbed impact energy were also investigated for the compatibilizers. A MA-g-PP having high molecular weight and low graft level was most effective in improving the investigated properties of a sunflower hull-reinforced polypropylene biocomposite.

\section{Introduction}

Natural fibers utilized as reinforcements in polymer matrices have produced biocomposites that have seen direct applications in different industries [1-3]. As an alternative to glass fiber, lignocellulosic long fibers such as hemp, flax, jute, sisal, and cotton are capable of maintaining the final cost-to-performance and weight-to-performance ratios of components, often with improved specific mechanical properties [2]. Improved sound and vibrational damping and potential end-of-service-life degradability are additional benefits realized by incorporating lignocellulosic long fibers in place of synthetic fibers [2].

Lignocellulosic fibers are suitable for use with thermoset resins, but encounter challenges upon compounding with thermoplastic polymers because of their size and wettability with high-viscosity resins. In addition, many of these fibers are not available in abundance in the United States, and as a result, must be imported [3]. These two challenges: (a) processability and (b) availability of supply, have caused the need for particulate-type, more accessible reinforcements for commodity thermoplastics. Introducing particulate lignocellulosic fibers has emerged as an approach to address these challenges. The flexibility in selection of lignocellulosic fibers increases for commodity biocomposites with flexibility in size reduction, for example, wood flour.

As the availability and quality of these natural fillers is prone to fluctuations at the source, the sustainable production of biocomposites warrants the investigation of novel fillers. One such particulate filler, sunflower hull (SFH), has been shown to be beneficial when incorporated into commodity polymers [4-6] such as polypropylene (PP) and acrylonitrile butadiene styrene (ABS). Utilizing such an agricultural coproduct is sensible because of its availability and steady supply and because of its value addition to a material that is often incinerated or discarded once its seeds have been removed. For sunflower growers, compounding the hulls into commercial thermoplastics is an attractive 
incentive. Biocomposite manufacturers also realize an economic benefit, as the low-cost filler now offsets a portion of their bulk material.

Nevertheless, building confidence in the industry requires an extensive analysis of material/property relationships and addressing the outstanding challenges that hinder implementation as a commercial blend. The effectiveness of compatibilizing (coupling) agents in improving the interfacial adhesion and thereby, mechanical properties in a hydrophilic PP and a hydrophilic natural fiber system such as wood flour is well established $[2,3]$. However, understanding the effects of these compatibilizing agents in a SFH/PP, which possesses a different composition, has received limited attention. The current study investigated the effect of two classes of chemical compatibilizers for PP, that is, acrylicacid-grafted PP and maleic-anhydride-grafted PP on the biocomposite mechanical properties.

The current study examined the mechanical properties of $20 \mathrm{wt} . \%$ SFH/PP biocomposites. Three different chemical compatibilizers based on their molecular weight and graft level were assessed for the benefits realized in mechanical properties. In addition to examining the capabilities of sunflower hull as a particulate reinforcement, the effects of chemical compatibilizers in improving the tensile strength were analyzed. The tensile, flexural, and impact properties were determined and were correlated to the interfacial interactions characterized using FTIR spectroscopy.

\section{Chemical Compatibilizers}

Polyolefins and lignocellulosic fibers are dissimilar in polarity, which reduces interfacial adhesion and thus lowers the ability for effective load transfer between the fiber and polymer chains. Several strategies have been devised to overcome this dissimilarity and to reduce the surface polarities through fiber surface treatments or through the addition of chemical compatibilizers $[2,3]$. The use of pelletized chemical compatibilizers compounded with a carrier resin is especially suitable for particulate-reinforced polyolefin systems, as they can be dry-mixed and compounded with the neat resin and the lignocellulosic fiber.

The chemical compatibilizers used in this study were molecules which were grafted to PP chains. Three compatibilizers were examined in this study; two maleic-anhydridegrafted (MA-g-PP) molecules and one acrylic-acid-grafted (AA-g-PP) molecule. The objective of adding these coupling agents was to establish covalent bonds between the polymer and the fiber surface, thus creating a pathway for load transfer through the compatibilizing molecule. The stresses experienced by the PP portion of the compatibilizer can thus be transferred across the covalent bond to the reinforcing fiber.

The effectiveness of a chemical compatibilizer molecule in improving interfacial load transfer can be correlated to (a) molecular weight, (b) the relative weight content of the grafted molecule with respect to the polymer chain (graft level), and (c) the overall reactivity of the grafted molecule. The molecular weight of a polymer compatibilizer
TABLE 1: Melt flow index and graft level of acrylic-acid and maleicanhydride-grafted polypropylene blends.

\begin{tabular}{|c|c|c|}
\hline & $\begin{array}{c}\text { Melt flow index } \\
(\mathrm{g} / 10 \mathrm{~min}) \\
\left(190^{\circ} \mathrm{C} / 2.16 \mathrm{~kg}\right)[5]\end{array}$ & $\begin{array}{c}\text { Graft Level } \\
\text { (wt.\%) }\end{array}$ \\
\hline Polybond 1002 (AA-g-PP) & 21.5 & 6.0 \\
\hline Polybond 3200 (MA-g-PP) & 110.1 & 1.0 \\
\hline $\begin{array}{l}\text { Licomont AR504 } \\
\text { (MA-g-PP) }\end{array}$ & - & $3.5[2]$ \\
\hline
\end{tabular}

describes its size and with increasing size, the ability of the molecule to interact with a greater number of PP chains through entanglement. The level of the grafted molecule in a compatibilizer indicates the number of attractive or reactive sites present per molecule. The graft level is provided by the vendor as a weight percentage of the grafted molecule. The reactivity of the grafted molecule is described as the number of chemical reactions in which the molecule may participate as well as the tendency of the molecule to participate in secondary bonding. The reactivity of the graft molecule dictates the formation of a covalent bond between the compatibilizer and fiber surface.

Compatibilizers of different molecular weight, graft level, and dissimilar grafted molecule were used in this study. The molecular weight of the compatibilizers was determined using a melt flow index (MFI) analysis. Fourier transforminfrared (FTIR) spectroscopy was used to examine carbonyl and hydroxyl functional groups that indicate the formation of secondary bonds. FTIR was also used to determine additional covalent bonds through the process of esterification.

\section{Materials and Experimental Methods}

\subsection{Materials}

3.1.1. Polymers and Compatibilizer. The base PP used in the formulations was supplied by Total Petrochemicals Inc, USA. as Total Polypropylene 3825 with MFI of $30 \mathrm{~g} / 10 \mathrm{~min}$ (ASTM D1238, Condition L, $230^{\circ} \mathrm{C} / 2.16 \mathrm{~kg}$ ).

The chemical compatibilizers used in this study are shown in Table 1 with melt flow index (determined experimentally) and graft level (provided by vendors) values. One MA-g-PP compatibilizer used was Licomont AR504, produced by Clariant International Limited. The second MA-gPP, Polybond 3200 was produced by Chemtura Corporation. The AA-g-PP compatibilizer used in this study was obtained as Polybond 1002, also from Chemtura Corporation. As the MA-g-PP compatibilizers were deemed incapable of being tested due to nonweighted flow under testing condition " $\mathrm{L}$ " as prescribed by ASTM D1238, the melt flow index for each compatibilizer was determined at a reduced temperature condition (Condition E, $190^{\circ} \mathrm{C} / 2.16 \mathrm{~kg}$ ). Licomont AR504 experienced non-weighted flow at this temperature, and hence, a melt flow index could not be determined. This compatibilizer was assumed to be the lowest relative molecular weight system of the three compatibilizers used in this study. 
3.1.2. Fiber. Sunflower Hulls were obtained from Red River Commodities Inc., Fargo, ND, USA. Wet chemistry analysis of the fiber constituents was performed by the North Dakota State University Animal Sciences Laboratory. The composition of the fiber was as follows: $44 \mathrm{wt} . \%$ cellulose, 17 wt. $\%$ hemicellulose, 5 wt. $\%$ protein, 2 wt. $\%$ crude fat, and $22 \mathrm{wt} . \%$ lignin. The sunflower hulls were ground to approximately a size of $250 \mu \mathrm{m}$ from the as-received state using a centrifugal mill (Retsch) equipped with a $250 \mu \mathrm{m}$ mesh.

3.2. Processing. The weight fraction of SFH was kept constant at $20 \mathrm{wt} . \%$, with the addition of $2 \mathrm{wt} . \%$ compatibilizer. Thus, a relative compatibilizer/fiber ratio of 0.10 was achieved. In addition, a control formulation was compounded which contained $20 \mathrm{wt}$ \% SFH without compatibilizer.

A Leistritz Micro-18GL/40D Extruder with corotating twin screws was used to compound the fiber/polymer. The fiber/polymer mixtures were dried at $80^{\circ} \mathrm{C}$ for a minimum of $16 \mathrm{~h}$ in a recirculating air oven before extrusion. The extrusion temperatures from feed zone to metering section were $149^{\circ} \mathrm{C}, 182^{\circ} \mathrm{C}, 185^{\circ} \mathrm{C}, 189^{\circ} \mathrm{C}, 195^{\circ} \mathrm{C}, 195^{\circ} \mathrm{C}$, and $195^{\circ} \mathrm{C}$. The die exit temperature was $190^{\circ} \mathrm{C}$.

The extruded compounds were dried at $80^{\circ} \mathrm{C}$ for a minimum of $24 \mathrm{~h}$ before injection molding on a 50-ton capacity Technoplas SIM 5080 Injection Molder. The zone temperatures from feed to metering zone were $193^{\circ} \mathrm{C}, 199^{\circ} \mathrm{C}$, $204^{\circ} \mathrm{C}$, and $210^{\circ} \mathrm{C}$, with a nozzle temperature of $204^{\circ} \mathrm{C}$. A nominal injection pressure was used as determined from vendor guidelines. Type A tensile specimens were molded for testing in accordance with ASTM D-638. Flexural and Izod Impact specimens were obtained from molded coupons $(158.8 \mathrm{~mm} \times 12.7 \mathrm{~mm} \times 3.2 \mathrm{~mm})$. The specimens were sectioned according to requirements in ASTM D790 and D256, respectively for flexure and Izod impact.

3.3. Nomenclature. The neat PP used in this study as a baseline was denoted as N. The $20 \mathrm{wt} . \%$ SFH/PP was used as a control and was denoted as C. The $20 \mathrm{wt} \% \mathrm{SFH} /$ $\mathrm{PP} /$ Compatibilizer grades were denoted based on their compatibilizing agent, that is, AR504, P3200, and P1002.

3.4. Mechanical Testing. Tensile testing was conducted according to ASTM D638, using an Instron 5567 load frame. Specimens were loaded at a rate of $5 \mathrm{~mm} / \mathrm{min}$ until fracture. Flexural testing was carried out in accordance with Procedure A of ASTM D-790, using an Instron 5567 load frame. As failure was not attained under 5\% flexural strain, all maximum flexural strengths were determined at 5\% strain.

Impact testing was performed in accordance with ASTM D256, using a Tinius Olsen Model Impact 104 pendulum impactor. Method A of the ASTM D256 standard was followed. For each of the mechanical tests conducted, a sample set of five test specimens was used. All testing was performed under standard room temperature conditions, that is, $23^{\circ} \mathrm{C}$ and $50 \%$ relative humidity.

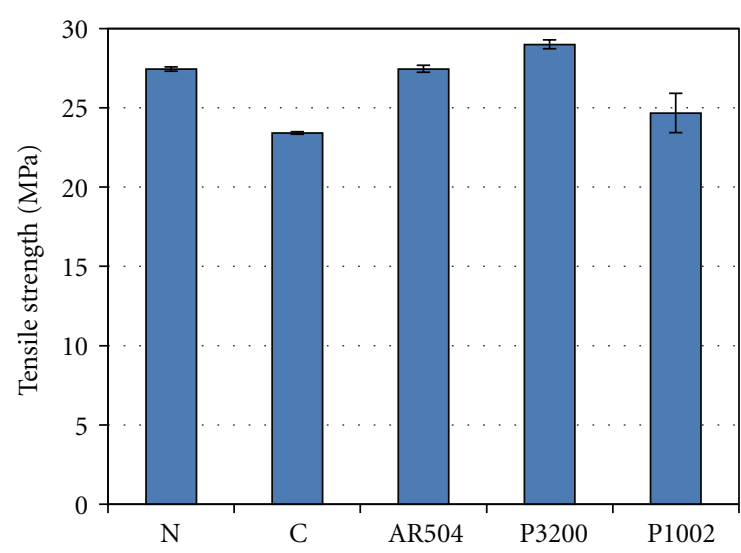

FIGURE 1: Comparison of tensile strength of neat polypropylene to that of sunflower reinforced polypropylenes with and without the inclusion of chemical compatibilizers. $\mathrm{N}$ corresponds to the neat, nonreinforced polypropylene, $\mathrm{C}$ to the reinforced control formulation without the addition of a compatibilizer.

3.5. Fourier Transform-Infrared Spectroscopy. FTIR spectra were acquired in the attenuated total reflectance (ATR) mode at $4 \mathrm{~cm}^{-1}$ resolution on a Thermo Scientific Nicolet 6700 FTIR spectrometer. Thirty-two scans per run were averaged to capture the mid-IR absorbance between $650 \mathrm{~cm}^{-1}$ and $4000 \mathrm{~cm}^{-1}$. The spectra were corrected for baseline shift and spectral noise.

\section{Results and Discussion}

\subsection{Mechanical Properties}

4.1.1. Tensile Properties. The tensile strength values of the biocomposites are shown in Figure 1. The inclusion of the sunflower hull fibers at a $20 \mathrm{wt} \%$ (C) resulted in a net reduction of $15 \%$ in the tensile strength as compared to N. Both MA-g-PP compatibilizers were found to improve the tensile strength of the blends compared to that of neat polypropylene, with P3200 showing a 6\% higher tensile strength over the neat polypropylene. AA-g-PP showed a net decrease of $10 \%$ in comparison to the neat tensile strength, but with a higher strength over $\mathrm{C}$ blend. A loss in tensile strength at a $20 \mathrm{wt} \% \%$ fiber loading is consistent with multiple natural fiber/PP studies involving wood flour [7-9], cotton [9], cellulose powder [10], and rice husk flour [11].

As shown in Figure 1, both maleic anhydride compatibilizers provided greater increases in tensile strength in comparison to the acrylic acid compatibilized blends. MFI analysis indicated that each MA-g-PP also possesses a lower molecular weight compared to the AA-g-PP compatibilizer. Often, a molecule having a relatively higher-molecularweight participates in a relatively greater number of chain entanglements, hence resulting in a greater load transfer. On the contrary, the performance of the compatibilizing molecules was found to be a stronger function of the behavior of the functionalizing group over the average molecular weight of the compound. 
The relative performance of AR504 and P3200 can be explained by considering both molecular weight and graft level of the molecules. AR504 possesses a greater number of potential sites for fiber attraction because of a higher graft level than P3200. The attraction between the fiber and maleic anhydride portion of the compatibilizer is critical; however, effective load transfer occurs if the compatibilizer is also entangled with a large fraction of PP chains. P3200 likely achieves a fiber/compatibilizer interaction that causes load transfer to a greater number of polymer chains due to a higher molecular weight, even with a lower graft level. Arbelaiz et al. [8] investigated a compatibilized flax fiber/PP system and found that at equivalent 0.1 compatibilizer/fiber loading, a maleated PP with higher molecular weight and lower graft level outperformed its counterpart in tensile strength. In the same study, the optimum tensile and flexural strengths were found between a ratio of 0.17 and 0.33 [8]. A similar work by Qiu et al. [10] with compatibilized cellulose powder/polypropylene blends showed a reduction in tensile strength occurring above a 0.16 loading ratio. In a study conducted by Arbelaiz et al. [8] on a compatibilized wood flour system, the critical loading ratio for improved tensile strength occurred between 0.05 and 0.10 . The optimal compatibilizer loading is a function of several aspects. The constituent composition of the fiber source, molecular weight, and graft level of the compatibilizer as well as the molecular weight of the base PP was different in the aforementioned studies.

The tensile modulus of the blends is shown in Figure 2. The addition of sunflower at $20 \mathrm{wt} . \%$ resulted in an increase in modulus of approximately $60 \%$. The effect of the compatibilizers on tensile modulus was less pronounced than their effect on tensile strength, with AR504 and P1002 showing a modulus value within the first standard deviation of the control, whereas P3200 exceeded the modulus of C by $4 \%$.

The inclusion of a particulate reinforcement with a modulus greater than that of PP causes an increase in the modulus of the biocomposite. The amount of reinforcement added imparts a strong effect on the modulus, whereas the inclusion of a compatibilizer does not show a strong effect in changing the tensile modulus. A study conducted by Dányádi et al. [7] showed a strong positive correlation between the volume fraction of wood and tensile modulus. In that work, six different compatibilizer/fiber loadings were investigated, and the tensile modulus changes showed no discernible trend. Arbelaiz et al. [8] found an improvement in tensile modulus with the incorporation of low $(\sim 0.03)$ compatibilizer/fiber loadings, but no additional improvements were realized at increased ratios. Within the two maleated compatibilizers, the low-molecular-weight system provided higher modulus consistently at all ratios of compatibilizer/fiber loadings.

4.1.2. Flexural Properties. The flexural yield strength values are shown in Figure 3. As seen, an increase in flexural strength of $16 \%$ was achieved by incorporating the sunflower hull filler. P3200 achieved the largest gain in strength and an additional $14 \%$ increase over the flexural strength of the control. The AR504 and P1002 compatibilizers showed

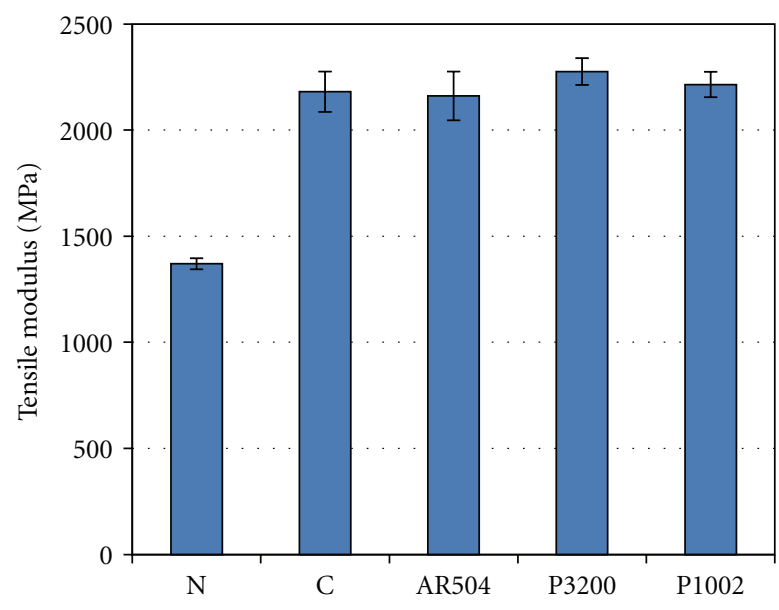

Figure 2: Comparison of the elastic tensile modulus of neat polypropylene to that of sunflower reinforced polypropylene blends with and without the inclusion of chemical compatibilizers.

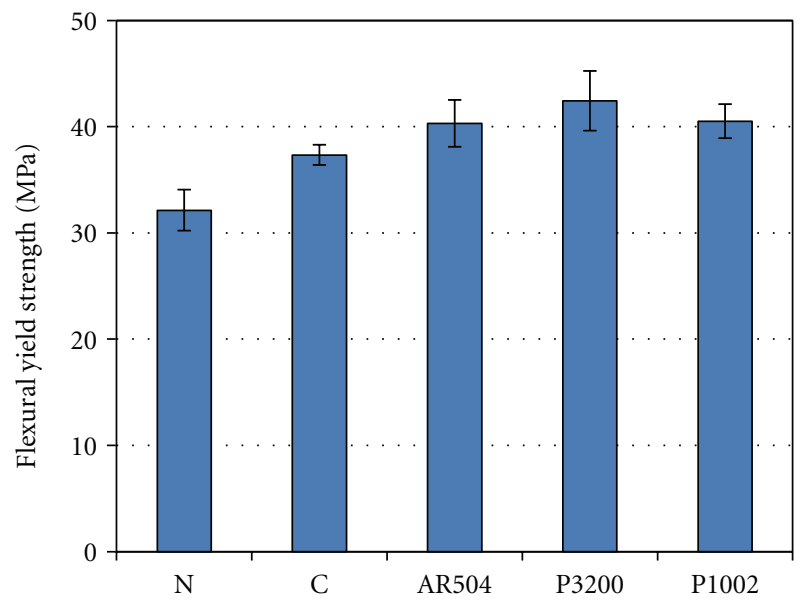

FIGURE 3: Comparison of flexural strength experienced at 5\% strain for neat and sunflower hull-reinforced polypropylenes with and without the inclusion of chemical compatibilizers.

similar increases, improving over the control by an average of $8 \%$.

Unlike the observed tensile strength, the inclusion of sunflower hull reinforcement results in a net gain in flexural strength as compared to the neat PP. As particulate reinforcements tend to improve the compressive strength of thermoplastics, and as flexural loadings result in both compressive and tensile stresses acting on the inner and outer material faces, respectively, the inclusion of SFH tends to increase flexural strength. P1002 demonstrated performance comparable to that of AR504 in flexural strength in comparison to $\mathrm{N}$. This behavior was in contrast to tensile properties, where a 2 wt.\% loading of P1002 was unable to attain the tensile strength of the neat PP. The improved tensile strength of the compatibilized blends, therefore, works to improve flexural strength due to the tensile stresses experienced.

Arbelaiz et al. [8] reported a compatibilizer/fiber loading greater than 0.1 in a maleated PP with relatively higher 
molecular weight and lower functionality cause increase in flexural yield strength. Similar to the tensile properties, a critical compatibilizer loading was realized and additional compatibilizer decreased the flexural strength after a critical fraction of MA-g-PP [8].

In the $\mathrm{C}$ grade, the presence of sunflower hull without the a compatibilizer caused a $38 \%$ increase in flexural modulus. The P3200 compound provided the greatest gain in modulus, about 3\% greater than the control.

The gains in flexural modulus showed a similar trend as tensile modulus (Figure 4), with each compatibilizer showing no discernible change from the control formulation. In Arbelaiz et al. [8], a lower-molecular-weight maleated compatibilizer outperformed a relatively higher molecular weight in all compatibilizer/fiber loading ratios.

4.1.3. Izod Impact Properties. The Izod impact strength of the compounds is shown in Figure 5. The addition of the SFH resulted in an 8\% decrease in impact resistance over the neat grade. Both MA-g-PP compatibilizers achieved a net reduction in absorbed energy, whereas the AA-g-PP compatibilizer experienced an absorbed energy approximately equal to that of C.

The inclusion of a particulate exhibiting repulsion from the bulk polymer chains results in an effective path for crack propagation under impact loads. The interfacial adhesion in a noncompatibilized blend allows for a greater amount of translation in the bulk compound chains, thus better dissipating the energy experienced in an impact event. An instrumented Charpy impact study performed by Hristov et al. [12] showed that for a wood flour/PP system versus a neat PP, approximately 25\% less specific energy was absorbed during crack initiation. Another finding of that study was the ability of a maleated compatibilizer to produce specific total energy absorption equivalent to that of neat PP. The maleated compound exhibited the highest specific initiation energy, and they attributed the impact performance to the ability to retard crack initiation. However, the compatibilizer and fiber were added in equivalent amounts, resulting in a ratio that is higher than most filler/compatibilizer ratios found in the literature. SEM microscopy performed on impact fractured wood flour/PP specimens by Oksman and Clemons [13] showed distinct regions of interfacial adhesion when maleated agents were incorporated. In areas where MA-g-PP improved the adhesion, fractured wood particles were held closely to the bulk matrix, with no voids between the two materials. In other regions of poor adhesion, voids were seen between the fiber and matrix.

As evident from Figure 5, the stronger interfacial bond achieved by both MA-g-PP compatibilizers resulted in the diminished ability to absorb energy in comparison to the AA-g-PP which created a relatively weaker interfacial bond. This behavior is consistent with the work of Dányádi et al. [14] on wood flour/PP blends. In that study, a MAg-PP compatibilizer with high molecular weight and low graft level was superior in impact resistance in comparison to a MA-g-PP having lower molecular weight and higher graft level. This trend was consistent at both 0.05 and

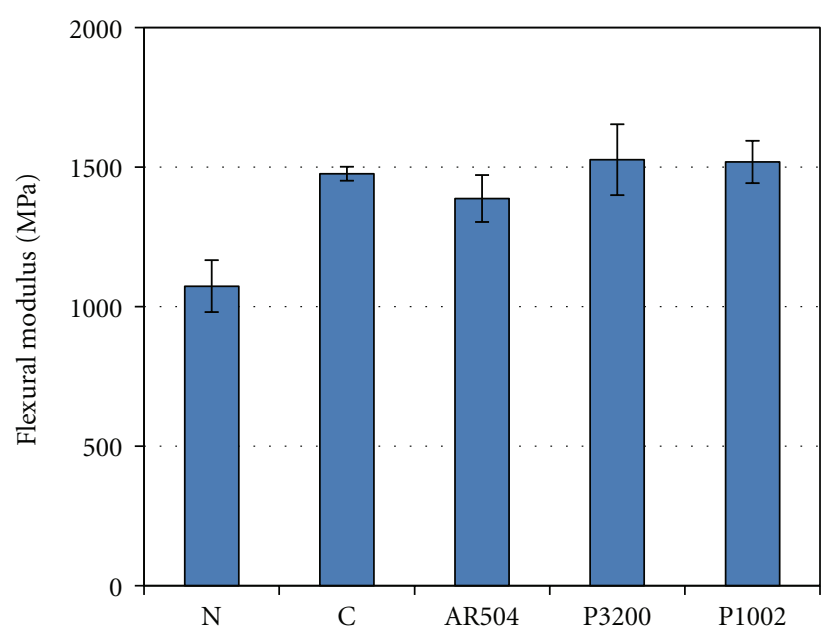

FIgure 4: Comparison of flexural modulus for neat and sunflower hull-reinforced polypropylene with and without the inclusion of chemical compatibilizers.

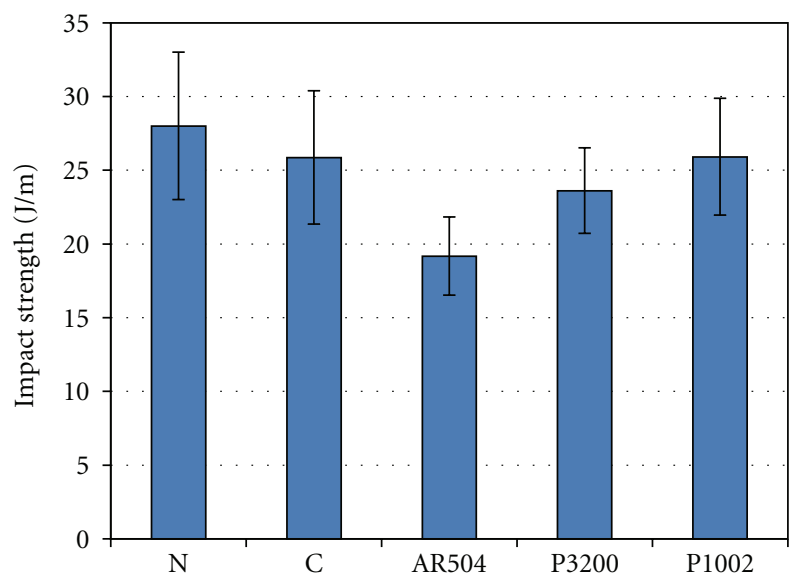

FIGURE 5: Comparison of absorbed impact energy for neat and sunflower hull-reinforced polypropylenes with and without the inclusion of chemical compatibilizers.

0.20 compatibilizer/wood flour ratios. Kim et al. [15] also performed Izod impact tests on five maleated compatibilizers having a 0.1 compatibilizer/fiber and found that the maleated compatibilizer with highest molecular weight and lowest graft level did not cause the greatest gain in absorbed energy. Hence, for compatibilizers, a minimum level of molecular weight and graft level necessitate the maximum effectiveness in improving impact strength.

Keener et al. [16] have proposed mechanisms that occur when insufficient or excessive molecular weight or graft level is present in a compatibilizer. As described previously, reduced molecular weight will not allow for proper chain entanglement by the compatibilizer. In contrast, excessive molecular weight may prevent the compatibilizer from locating next to a fiber surface. In addition, a low graft level does not allow for sites at which the compatibilizer can attach to the fiber surface; whereas an excessive graft level may 


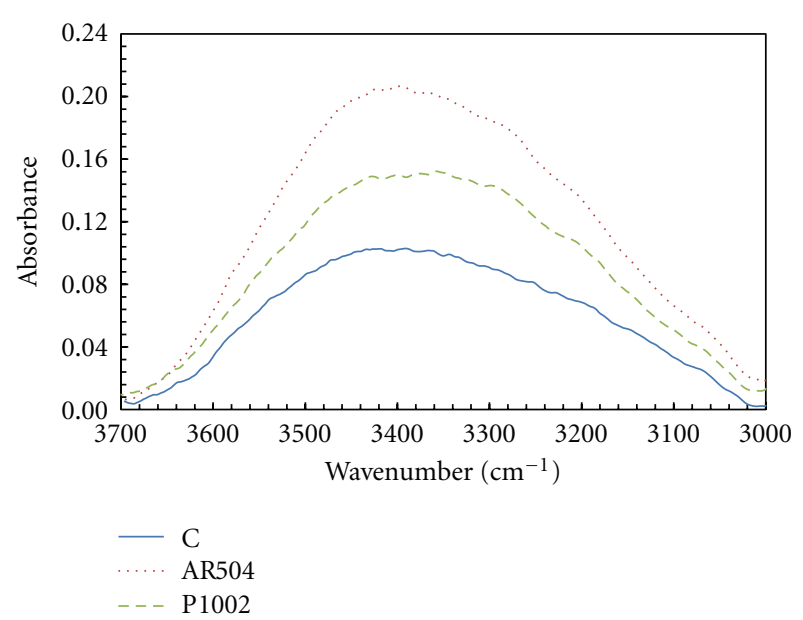

FIGURE 6: Infrared absorbance of sunflower hull/PP blends containing no compatibilizer, maleated AR504 compatibilizer, and acrylated P1002 compatibilizer. Absorbance in $3000 \mathrm{~cm}^{-1}$ to $3700 \mathrm{~cm}^{-1}$ range is indicative of the hydroxyl functional group.

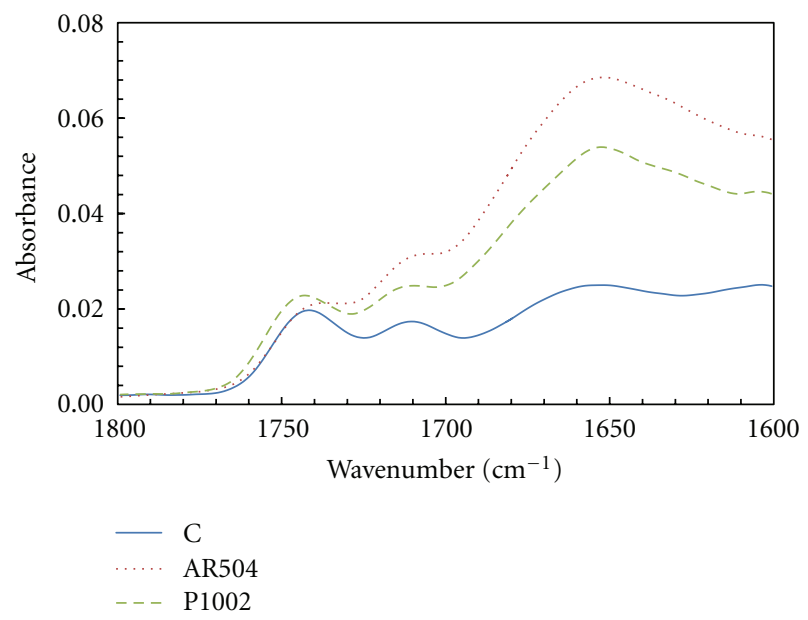

Figure 7: Infrared absorbance of sunflowerhull/PP blends. Absorbance in $1600 \mathrm{~cm}^{-1}$ to $1800 \mathrm{~cm}^{-1}$ range is indicative of the carbonyl functional group.

hold the compatibilizer close to the fiber and prevent the polypropylene from entangling in the bulk PP.

4.2. Fourier Transform-Infrared Spectra. The FTIR spectra are shown in Figures 6 and 7. Absorbances in the $1600 \mathrm{~cm}^{-1}$ to $1800 \mathrm{~cm}^{-1}$ and $3000 \mathrm{~cm}^{-1}$ to $3700 \mathrm{~cm}^{-1}$ region are shown respectively. The functional groups contributed by the compatibilizing molecules were compared to the absorbance of the control formulation. AR504 was selected of the two maleated PPs for FTIR spectroscopy, as its relatively higher graft level increases the probability of participation in esterification.

In both absorbance ranges, AR504 achieved greater absorbance over P1002 despite of the lower graft level. This result can be explained by considering the low molecular weight of the AR504 system, as the graft level is considered a percentage of the total molecular weight of the compatibilizer.

As the absorbance level corresponds to the number of functional groups, a greater amount of functional groups should result in the formation of a greater number of secondary bonds. However, the AR504 and P1002 formulations exhibited similar mechanical performance. In addition, the higher properties of the low-graft-level P3200 suggested that secondary bonding did not affect the effectiveness of the compatibilizer.

The absorbance peak in the carbonyl region signifying esterification was analyzed. Kazayawoko et al. [17] has proposed a hypothetical model of esterification between maleated PP and hydroxyl groups located on the fiber. A similar model was proposed by $\mathrm{Li}$ and Matuana [18], which described possible esterification between acrylic-acidgrafted polypropylene and hydroxyl groups of the fiber. The formation of this bond supports the ability of the compatibilizers to improve interfacial adhesion, as a covalent bond is formed in the process that joins the compatibilizer to the fiber surface. The location of the ester carbonyl peak is specific to the polymer and fiber. Kazayawoko et al. [17] reported the ester carbonyl peaks in wood fiber/PP systems at $1730 \mathrm{~cm}^{-1}$. In Kim et al. [15], the ester peaks were shown between $1739 \mathrm{~cm}^{-1}$ and $1741 \mathrm{~cm}^{-1}$.

Figure 7 shows absorbance peak occurs at approximately $1741 \mathrm{~cm}^{-1}$ in all systems. The ester peak was most pronounced in the AA-g-PP compatibilized system. Other peaks found in this range $\left(\sim 1710 \mathrm{~cm}^{-1}\right.$ and $\left.\sim 1650 \mathrm{~cm}^{-1}\right)$ were consistent in all systems and there by not likely indicative of the ester functional group. The FTIR spectra supported the occurrence of esterification reaction weakly in the investigated systems, regardless of a maleated or acrylated functional group. The esterification between a maleated PP compatibilizer and a lignocellulosic fiber was verified using FTIR in previous works $[18,19]$. In [18], Li et al. detected esterification in wood fiber/polyethylene systems compatibilized with both maleated and acrylated polyethylene, showing that acrylic acid can cause esterification.

\section{Conclusions}

Sunflower hull as a particulate reinforcement at a $20 \mathrm{wt} . \%$ loading in PP result in a net increase in tensile modulus, flexural strength, and flexural modulus. Chemical compatibilizers at a 0.1 compatibilizer to fiber ratio caused greater increases in the investigated mechanical properties, including a major gain in tensile strength. These improvements were accompanied by a reduction in the impact energy absorption that decreased further with addition of a compatibilizer in the blend.

A performance comparison of three chemical compatibilizers was performed to analyze effectiveness in improving interfacial adhesion. At an equivalent weight loading, maleic anhydride compatibilizers caused greater increases in properties over an acrylic acid compatibilizer having higher molecular weight and graft level. Within the two MA-g-PP agents, higher molecular weight and lower graft level caused 
greater gains in mechanical properties. The formation of covalent ester bonds was weakly supported by FTIR.

Optimal compatibilization can be achieved by determining the appropriate balance between molecular weight and graft level in the compatibilized molecule. A compatibilizer with low graft level and high molecular weight, such as the maleated P3200, can be most effective in improving interfacial adhesion and stress transfer to lignocellulosic fibers.

\section{Acknowledgments}

This study was conducted with funding support from the North Dakota Corn Council. The authors would like to thank Red River Commodities Inc. (Fargo, ND, USA) for a donation of material and also the North Dakota State University Pilot Plant and research specialist Darrin Haagenson for his technical assistance.

\section{References}

[1] R. Malkapuram, V. Kumar, and Y. Singh Negi, "Recent development in natural fiber reinforced polypropylene composites," Journal of Reinforced Plastics and Composites, vol. 28, no. 10, pp. 1169-1189, 2009.

[2] A. K. Mohanty, M. Misra, and L. T. Drzal, "Sustainable Bio-Composites from renewable resources: opportunities and challenges in the green materials world," Journal of Polymers and the Environment, vol. 10, no. 1-2, pp. 19-26, 2002.

[3] A. K. Mohanty, M. Misra, and L. T. Drzal, "Surface modifications of natural fibers and performance of the resulting biocomposites: an overview," Composite Interfaces, vol. 8, no. 5, pp. 313-343, 2001.

[4] G. Sui, W. Zhong, M. Fuqua, and C. Ulven, "Properties of polypropylene composites fabricated using twin-screw extrusion," in Proceedings of the 16th International Conference on Composite Materials, Kyoto Japan, July 2007.

[5] V. S. Chevali, M. A. Fuqua, S. Huo, and C. A. Ulven, "Utilization of agricultural by-products as fillers and reinforcements in ABS," SAE International Journal of Materials and Manufacturing, vol. 3, no. 1, pp. 221-229, 2010.

[6] V. Chevali and C. Ulven, "Effect of extrusion screw speed on biocomposite thermo-mechanical properties," International Journal of Sustainable Engineering, vol. 5, no. 1, pp. 38-46, 2012.

[7] L. Dányádi, T. Janecska, Z. Szabó, G. Nagy, J. Móczó, and B. Pukánszky, "Wood flour filled PP composites: compatibilization and adhesion," Composites Science and Technology, vol. 67, no. 13, pp. 2838-2846, 2007.

[8] A. Arbelaiz, B. Fernández, J. A. Ramos, A. Retegi, R. LlanoPonte, and I. Mondragon, "Mechanical properties of short flax fibre bundle/polypropylene composites: influence of matrix/fibre modification, fibre content, water uptake and recycling," Composites Science and Technology, vol. 65, no. 10, pp. 1582-1592, 2005.

[9] S. J. Kim, J. B. Moon, G. H. Kim, and C. S. Ha, "Mechanical properties of polypropylene/natural fiber composites: comparison of wood fiber and cotton fiber," Polymer Testing, vol. 27, no. 7, pp. 801-806, 2008.

[10] W. Qiu, F. Zhang, T. Endo, and T. Hirotsu, "Preparation and characteristics of composites of high-crystalline cellulose with polypropylene: effects of maleated polypropylene and cellulose content," Journal of Applied Polymer Science, vol. 87, no. 2, pp. 337-345, 2003.

[11] H. S. Yang, H. J. Kim, H. J. Park, B. J. Lee, and T. S. Hwang, "Effect of compatibilizing agents on rice-husk flour reinforced polypropylene composites," Composite Structures, vol. 77, no. 1, pp. 45-55, 2007.

[12] V. N. Hristov, R. Lach, and W. Grellmann, "Impact fracture behavior of modified polypropylene/wood fiber composites," Polymer Testing, vol. 23, no. 5, pp. 581-589, 2004.

[13] K. Oksman and C. Clemons, "Mechanical properties and morphology of impact modified polypropylene-wood flour composites," Journal of Applied Polymer Science, vol. 67, no. 9, pp. 1503-1513, 1998.

[14] L. Dányádi, K. Renner, Z. Szabó, G. Nagy, J. Móczó, and B. Pukánszky, "Wood flour filled PP composites: adhesion, deformation, failure," Polymers for Advanced Technologies, vol. 17, no. 11-12, pp. 967-974, 2006.

[15] H. S. Kim, B. H. Lee, S. W. Choi, S. Kim, and H. J. Kim, “The effect of types of maleic anhydride-grafted polypropylene (MAPP) on the interfacial adhesion properties of bio-flourfilled polypropylene composites," Composites A, vol. 38, no. 6, pp. 1473-1482, 2007.

[16] T. J. Keener, R. K. Stuart, and T. K. Brown, "Maleated coupling agents for natural fibre composites," Composites A, vol. 35, no. 3, pp. 357-362, 2004.

[17] M. Kazayawoko, J. J. Balatinecz, and R. T. Woodhams, "Diffuse reflectance Fourier transform infrared spectra of wood fibers treated with maleated polypropylenes," Journal of Applied Polymer Science, vol. 66, no. 6, pp. 1163-1173, 1997.

[18] Q. Li and L. M. Matuana, "Effectiveness of maleated and acrylic acid-functionalized polyolefin coupling agents for HDPE-wood-flour composites," Journal of Thermoplastic Composite Materials, vol. 16, no. 6, pp. 551-564, 2003.

[19] M. Kazayawoko, J. J. Balatinecz, and L. M. Matuana, "Surface modification and adhesion mechanisms in woodfiberpolypropylene composites," Journal of Materials Science, vol. 34, no. 24, pp. 6189-6199, 1999. 

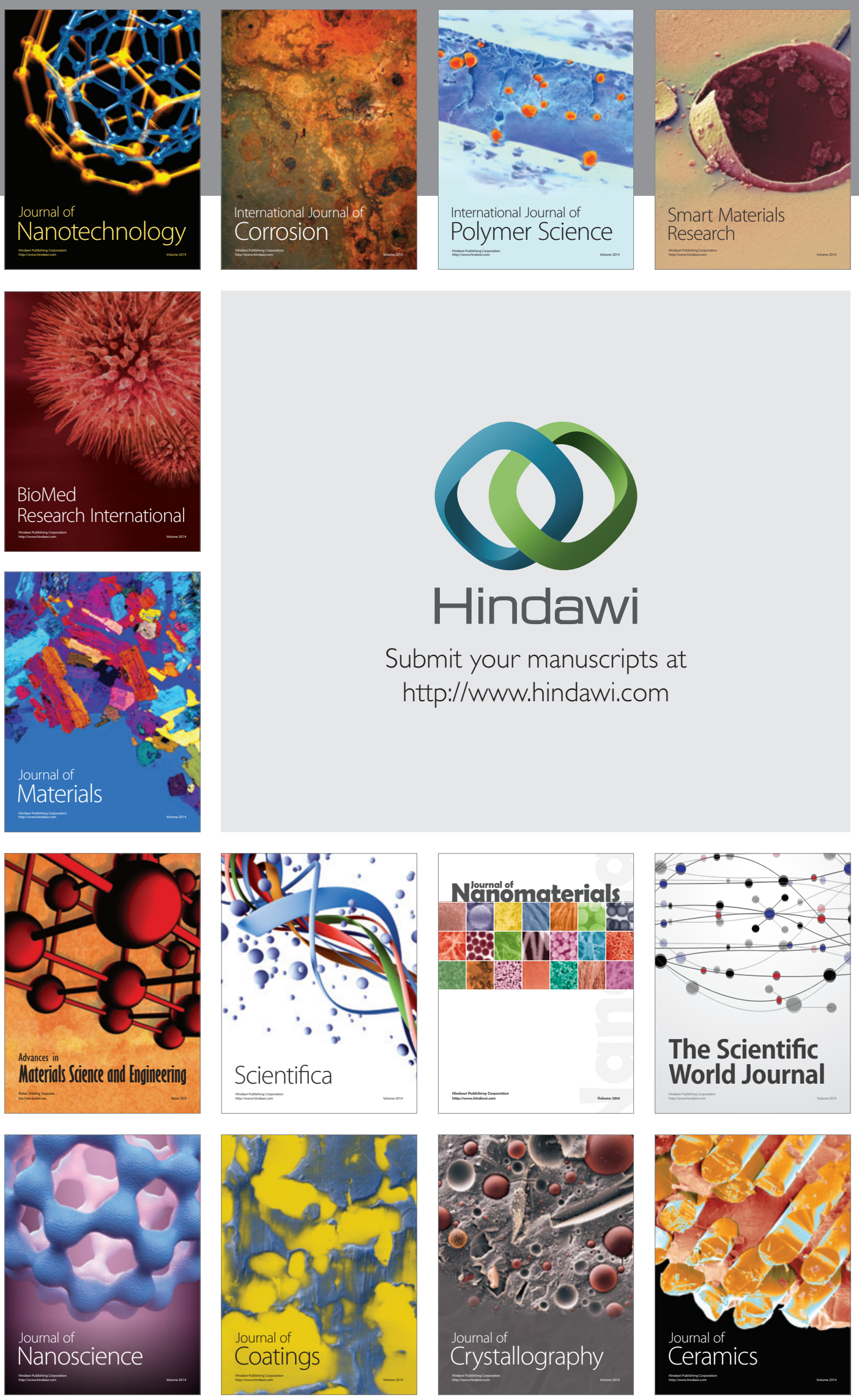

The Scientific World Journal

Submit your manuscripts at

http://www.hindawi.com

\section{World Journal}

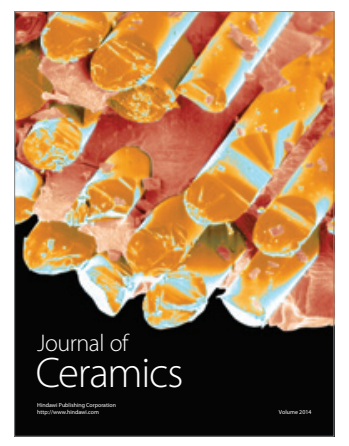

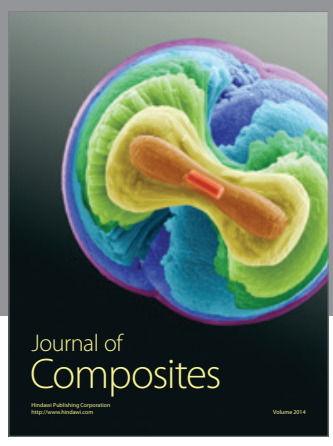
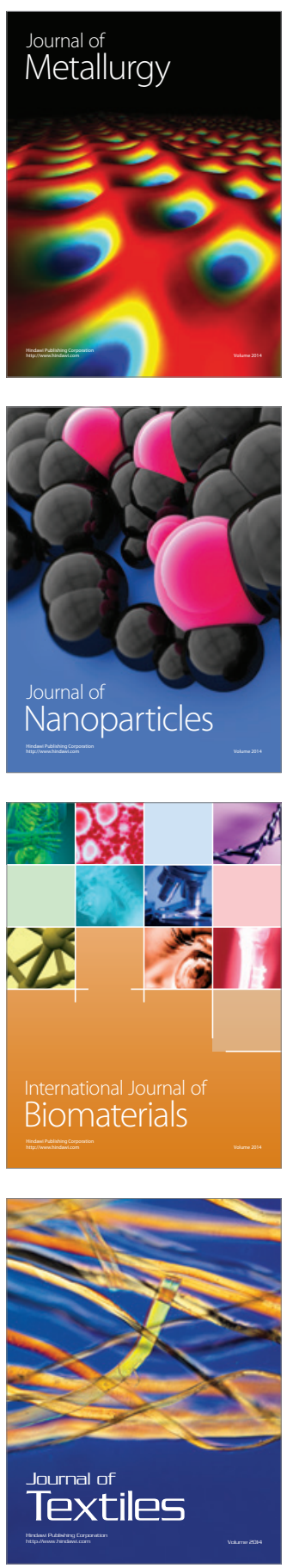